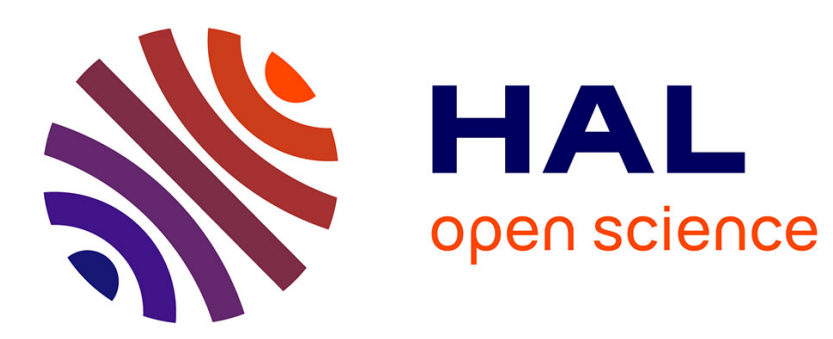

\title{
Civil Liability, Safety and Nuclear Parks: Is Concentrated Management Better?
}

Gérard Mondello

\section{To cite this version:}

Gérard Mondello. Civil Liability, Safety and Nuclear Parks: Is Concentrated Management Better?. 2011, pp.26. hal-00727252

\section{HAL Id: hal-00727252 \\ https://hal.science/hal-00727252}

Submitted on 3 Sep 2012

HAL is a multi-disciplinary open access archive for the deposit and dissemination of scientific research documents, whether they are published or not. The documents may come from teaching and research institutions in France or abroad, or from public or private research centers.
L'archive ouverte pluridisciplinaire HAL, est destinée au dépôt et à la diffusion de documents scientifiques de niveau recherche, publiés ou non, émanant des établissements d'enseignement et de recherche français ou étrangers, des laboratoires publics ou privés. 
FONDAZIONE ENI

ENRICO MATTEI

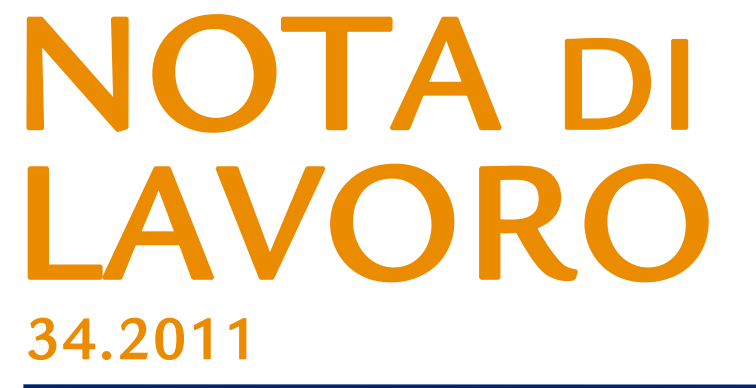

Civil Liability, Safety and Nuclear Parks:

Is Concentrated

Management Better?

By Gérard Mondello, University of Nice Sophia Antipolis, CREDECO, GREDEG, UMR 6727, CNRS 


\title{
SUSTAINABLE DEVELOPMENT Series \\ Editor: Carlo Carraro
}

\section{Civil Liability, Safety and Nuclear Parks: \\ Is Concentrated Management Better?}

By Gérard Mondello, University of Nice Sophia Antipolis, CREDECO, GREDEG,UMR 6727, CNRS

\begin{abstract}
Summary
Ultra-hazardous risky activities as nuclear industry cannot be considered as "normal industries" i.e. industries without abnormal environmental and health risks. Consequently, the industrial organization of these specific sectors is of the utmost importance. This paper aims at studying this question. We focus on the associated costs of prevention and civil liability. We analyze how civil liability rules may contribute to extend or to discourage the expansion of nuclear parks to new operators. The paper compares the consequences of extending the management of nuclear stations to several independent operators. This question can apply to the unification process of the European electricity market in which several public and private nuclear power operators are running. The paper shows that the choice between either a monopolistic scheme (one operator managing several plants) or a decentralized one (one operator by station) depends on the condition of application of the legal civil liability regime and on the strength of the safety control exerted by the Nuclear Regulatory Authorities. It is shown that when the control is high, then the safety costs generated by the monopolistic organization are less than the same costs of a decentralized one. However, conditions on the insurance policy can mitigate this result.
\end{abstract}

Keywords: Strict Liability, Electric Energy, Nuclear Plants

JEL Classification: Q5, Q58, Q53, K23, L13, L52, L94

I'd like to thank Evens Salies for the long discussions we had about this contribution. All errors are of my sole responsibility.

Address for correspondence:

Gérard Mondello

University of Nice Sophia Antipolis

CREDECO, GREDEG,UMR 6727, CNRS

250, rue Albert Einstein

06560 Valbonne Sophia Antipolis

France

Phone: +33493954327

Fax: +334 93653798

E-mail: gerard.mondello@gredeg.cnrs.fr

The opinions expressed in this paper do not necessarily reflect the position of Fondazione Eni Enrico Mattei

Corso Magenta, 63, 20123 Milano (I), web site: www.feem.it, e-mail: working.papers@feem.it 


\title{
Civil Liability, Safety and Nuclear Parks: \\ Is Concentrated Management Better?
}

\author{
Gérard Mondello* \\ University of Nice Sophia Antipolis, \\ CREDECO, GREDEG,UMR 6727,CNRS. \\ 250, rue Albert Einstein \\ 06560 Valbonne Sophia Antipolis- France. \\ Tel.: + 33-4-93954327-fax:+ 33-4-93653798, \\ gerard.mondello@gredeg.cnrs.fr
}

March 2011

JEL Classification : Q5, Q58, Q53, K23, L13, L52, L94

Key words: Strict liability, Electric Energy, nuclear plants, limited liability, concentration

\footnotetext{
* I would like to thank Evens Salies for the discussions we had about this contribution. All errors are of my sole responsibility.
} 


\section{Introduction}

From the end of the $20^{\text {th }}$ Century to the beginning of the $21^{\text {th }}$ one, nuclear power industry developed fast because of the regular price crisis that oil and gas energies suffered during this period. Nuclear energy has been seen as a powerful and efficient complement or partial substitute to them. However, this growth has been interrupted due both to the 1979 Three Miles Island ${ }^{1}$ accident and the 1986 Tchernobyl catastrophe that froze the nuclear impetus for long. At the beginning of the 2000 years, new oil and gas crisis and the new environmental concerns about GHG emissions and their mandatory reduction ${ }^{2}$ helped the revival of the nuclear industry ${ }^{3}$. This state of matter could be considered as true until $11^{\text {th }}$ March 2011 before that the 9.0-magnitude Tohoku earthquake and its following tsunami devastated Japanese northeast coast. The subsequent catastrophic consequence has been the knocking out of the reactor cooling systems of the Fukushima Daiichi and Daini electronuclear plant. This induced leakage of irradiated contaminant that threats populations located in the plant's vicinity, the supply of fresh water, the sea resources and the agriculture products on a large scale in Japan.

As for the Three Miles Island ${ }^{4}$ and Tchernobyl accidents, by its severity, the Fukushima disaster undermines (and will undermine) the defenders' position of the nuclear option. Already, in Europe, some countries put into question their recent nuclear power programs as Germany and Italy for instance. Anyway, the industrial and economic consequences of this catastrophic event are still unknown because at the present time (April 2011) Japanese authorities are far from getting control on the situation: the Fukushima catastrophe is still going on and developing. Consequently, these events will spark a close questioning of the viability and the safety of the whole nuclear plants in the World. Without doubt, after that, some stations will be closed or refurbished.

However, from an economic viewpoint, the present situation could be quite different from what the past showed. Indeed, in the eighties, nuclear accidents entailed either the break down or the serious slow down of the electro-nuclear projects in most Countries. By now, emergent countries are deeply involved in the development of their energy plan and going back to a fossil energy alternative could be difficult for them. Hence, in spite of the Fukushima accident, nuclear program will go on spreading, even at slower rates.

\footnotetext{
${ }^{1}$ Rogovin and Frampton, (1980).

${ }^{2}$ See e.g. the Intergovernmental Panel on Climate Change, Fourth Assessment Report, (2007).

${ }^{3}$ So for example the Ampere(2000) report.

${ }^{4}$ Rogovin and Frampton, (1980).
} 
This structural trend and this tragic accident put spotlights on the very sensitive question of the electro-nuclear plants safety. Even if nuclear catastrophes are deemed to occur with very low probability ${ }^{5}$, they have far-reaching consequences for health and the Environment. Furthermore, the very recent history has shown that unexpected scenarios can develop as in Fukushima where the tsunami damaged simultaneously its four reactors.

As a consequence, giving up the nuclear sector is a long run project and more probably, nuclear programs will last several more decades. Then, it is natural and legitimate to consider that, nowadays, the industrial organization of this ultra-hazardous risky industry is becoming a major stake ${ }^{6}$. Initially, Governments boosted the development of electro-nuclear industry in the wake of the development of military activities. However at the present, private interests are growingly interested and involved in the development of nuclear programs. This can take the shape of public-private participation. For instance, in the United States from July 1999 to September 2008, eighteen US nuclear plants changed ownership ${ }^{7}$. The firm Tokyo Electric Power Company (TEPCO) in Japan is private and manages three nuclear plants. Private firms are all the more encouraged to invest in this sector by the international institutional improvement of the coverage conditions of third party damages. The temptations to break State monopolies in this sector are great. Furthermore, the unification of the electricity market (as it is the case in Europe) induces several nuclear operators to live together. Taking into account these factors leads to wonder whether a greater safety is guaranteed by a centralized organization of the nuclear sector, or whether the arrival of new comers can contribute to increase the level of care and protection under a decentralization process. Since the end of the nineties this point is controversial, (see for instance Varley and Paffenbarger (1998), or still AEN-OCDE (2000)). The recent Japanese catastrophe reopens this debate following the Italian and German decisions.

\footnotetext{
5 "It is sometimes argued that for, so-called" Damocles risks", i.e. risks with a very high damage and a low probability, the risk assessment of the public is not proportional to the risk. The occurrence of a very high damage should be avoided, even if the costs for the avoidance are much higher than the expectation value of the damage. However past attempts to quantify this effect have not been successful or accepted, so there is currently no accepted method on how to include risk aversion in such an analysis. Consequently it is currently not taken into account within the ExternE methodology. Research on how to assess this, for example with participatory approaches, is clearly needed.”, Bickel and Rainer (2005), p. 226

${ }^{6}$ See for instance protests against the building of a new nuclear power station in Armenia at Metzamor who sits in a seismic zone that has suffered one of the worst earthquakes in modern history.

http://www.nuclearpowerdaily.com/reports/Environmentalists_decry_risks_of_new_Armenia_nuclear_reactor_9 99.html.

${ }^{7}$ Source Nuclear Energy Institute. http://www.nei.org/resourcesandstats/documentlibrary/reliableandaffordableenergy/graphicsandcharts/usnuclear plantsales/
} 
This paper assesses on a theoretical basis how civil liability rules influence the entrance of new operators on the electronuclear production. This is done by appraising the consequences on care levels of the splitting-up of an electro-nuclear park into independent entities. Performance is evaluated by the level of safety and the global cost of liability and prevention. Choosing between centralizing and decentralizing the organization of a park of nuclear plants depends on several factors as, for instance, the nature of the legal civil liability regime, the strength of the control exerted by the Nuclear Regulatory Authorities and the nature of the insurance policy. When the control is low, we show that both structures are equivalent because of the similarity of their safety costs. However, under a high control, a centralized organization generates lesser safety costs compared to a decentralized structure though this opinion should be moderated. Indeed, the present model shows that a high insurance cover may favor the decentralized organization. This may be done, for instance, by pooling the financial resources of different operators as in the US Price-Anderson Act of 1957, or the German insurance system based on a large extension of the operators' liability. This question has policy implications. For instance, it may be applied to the unification process of the European electricity market characterized by several public and private nuclear operators $^{8}$.

For this reason, compared to the wide field of the electro-nuclear economics, this paper will deal neither with the economic benefits of nuclear energy compared to other energies (MIT (2003), (2009), Bickel and Rainer (2005)), nor with the operating conditions of the nuclear deal with price uncertainty (Gollier, Proult, Thais and Walgenwitz (2004), Linares and Conchado, (2009)), nor with the question of decommissioning plants, and, still, nor with the reprocessing of nuclear waste. Its argument borrows some features of the debate about civil liability in the electro-nuclear industry. Most of these controversial contributions (Dubin and Rothwell (1990), Heyes and Heyes, (1998), (2000a), 2000b), Faure and Borre (2008), Faure and Fiore (2009), Rothwell (2001)) show that putting ceiling on the level of repairs comes at subsidizing implicitly this industry ${ }^{9}$ and tends to let unpaid the externality costs. However, this paper will not take this road. Starting from the civil liability question, it focuses rather on understanding the best economic organization scheme that insures the best safety level.

\footnotetext{
${ }^{8}$ In October 1, 2010, in Europe, Russia and Ukraine included, there is a total of 195 nuclear power plant units with an installed electric net capacity of $170 \mathrm{GWe}$ in operation in Europe 19 units with $16,9 \mathrm{GWe}$ were under construction in six countries. (source European Nuclear Society).

http://www.euronuclear.org/info/encyclopedia/n/nuclear-power-plant-europe.htm

${ }^{9}$ See also the synthesis achieved by Carroll and Froggatt (2007).
} 
A first paragraph explains the nature of civil liability in the electro-nuclear sector. It underlines the importance of the ceiling of the level of repairs for inducing private operators to enter the market. A second paragraph describes the model based on the comparison of the expected costs of the organization of a park of two stations managed either by a unique operator or by two operators. A third one compares each kind of organization considering the level of effort dedicated to safety. A fourth one concludes and gives some policy recommendation.

\section{Civil liability and the development of the nuclear industry}

Before 1988, Soviet Union acceded neither to any nuclear conventions nor to national nuclear liability law and, after the Tchernobyl 1986 disaster, this Country escaped to the duty to compensate damages to health, crops of national and international economies. To avoid future detrimental situations, the international community amended the existing nuclear conventions $^{10}$. The 1988 Joint Protocol linked together the IAEA's Vienna Convention on Civil Liability for Nuclear Damage of 1963 and the OECD's Paris Convention on Third Party Liability 1960. Protocols amending the Paris Convention and the Brussels Convention were signed on February 12, 2004.

The joint protocol promotes a strict liability regime but maintains the liability limitation principle settled by the previous international conventions ${ }^{11}$. These last one set on a global framework that national legislation can make more, but not less, stringent. Under the Joint Protocol, the operators of civil nuclear facilities are made strictly liable for damage resulting from nuclear incidents. Furthermore, there is an obligation of insurance or financial guarantee by the operator up to the fixed liability amounts in order to guarantee the availability of funds. This disposition is submitted to the approval of the Members States. What complicates things is that the States may have signed one convention but another one. This contributes to differentiate the liability ceilings of the Members States. To put in a nutshell, we can quote the 2005 report Eurotom on the harmonization of nuclear civil liability rules in Europe.

"In sum, the protection of victims of nuclear accidents, the obligations of nuclear operators, transporters, (re-)insurers and public authorities in the EU Member States are governed by a patchwork of diverse legal regimes: ( $i$ ) the liability of some operators is unlimited, whereas others have a capped liability; (ii) the operators' insurances differ both as

\footnotetext{
${ }^{10}$ See for instance, Faure and Fiore (2009),

${ }^{11}$ Under the Joint protocol of 1988, the operator's liability is absolute, i.e. the operator is held liable irrespective of fault, except for "acts of armed conflict, hostilities, civil war or insurrection", terrorism acts do not enter in the exclusion category.
} 
regards their coverage and payable fees; and (iii) the obligation to compensate victims of a nuclear accident differs both as regards the damages covered and the payable amounts."

Why do States choose the ceiling of redress rather than applying some "standard" strict civil liability regime? In fact, the hugeness of repairs due to nuclear hazards coupled with a civil strict liability regime prevents private firms to exert an activity in the nuclear field. Schwartz, (2006, p.39) summarizes the point very well: “With no protection against a liability that was potentially unlimited both in time and amount, nuclear plant owners/operators, builders and suppliers were understandably hesitant to commit to the development of the industry."

Therefore, developing nuclear industry involves relieving nuclear operators of the burden of potentially ruinous liability claims ${ }^{12}$. The governments ceiled the amount of compensation payable to victims by liable operators in the aim at avoiding judgment proofness. Under the evolution of international agreements, the caps to liability may be subject to institutional changes and, generally, the tendency is to increase the level of the ceiling. For instance, under the Brussels Convention, in France, the operator's liability is limited to $€ 91.5$ million per nuclear accident in a facility and to $€ 22.9$ million per nuclear accident during transportation. The State in which the accident occurred will be liable for the compensation of victims up to a maximum of $€ 228.6$ million. Above this amount, the signatory's members of the Brussels Convention contribute collectively to compensation up to a ceiling of $€ 381.1$ million. However, under the 2004 protocol, the availability of compensation amounts is much greater and covers a greater number of victims and collateral damages. Accordingly, the operator's liability is around $€ 700$ million per nuclear accident and $€ 80$ million per nuclear accident during transportation. The responsible State of a nuclear damage will be liable for amounts above the $€ 700$ million up to a maximum amount of $€ 1,200$ million. Above this amount, the States that are a party to the Brussels Convention will be contribute to a maximum amount of $€ 1,500$ million.

In the USA, the Price-Anderson Act of 1957 rules the civil liability for damages caused by a nuclear accident. Since the 1988 amendments, nuclear power plant licensees must purchase the maximum amount of commercial liability insurance available in the private market at a reasonable price. This is currently \$200 million per plant. In addition, all nuclear power plant licensees must participate in a joint-insurance pool. In the case of a nuclear

12 More explicit still is The "Exposé des Motifs" for the 1960 Paris Convention that considers that "unlimited liability could easily lead to the ruin of the operator without affording any substantial contribution to compensation for the damage caused" (Exposé des Motifs, Motif 45). 
accident whose costs exceed the first layer of private insurance coverage, each nuclear plant is obligated to make payments of up to $\$ 88$ million to cover any additional costs up to about $\$ 9.3$ billion at the present time. The compensation provision of both the first and the second layers of insurance are "no fault" and are not subject to civil liability litigation. The financial cap is fixed to $\$ 9.5$ billion and beyond this limit there are no further financial obligations.

\section{The Model}

We compare the cost structure dedicated to safety and civil liability of two electronuclear power structures. The first one is centralized i.e. a unique operator (public or private) manages two perfectly similar nuclear plants. The centralized structure may be split up and the two plants will be managed by two distinct operators. Each of them will own and manage a unique plant. "Similar" plant means that each one belongs to the same generation. Putting it otherwise, each one is built on the same engineering structure and has the same production capacity $^{13}$.

\subsection{Notations and assumptions}

\subsubsection{The operators}

The considered economy comprises two similar electro-nuclear plants indexed by $j, j=1,2$. The index $\mathrm{M}$ denotes the unique operator (sometimes called also the "monopolist") and by no letter when ambiguity is impossible. When the independent operators manage them, the index will be they will be denoted by $i, i=1,2$ (operator $i$ manages one plant).

Assumption 1: The operators are risk neutral.

Assumption 2: Both plants are similar.

We consider now the operators' financial capacity for redress. This capacity tallies with the total available asset needed to repair the consequences of a major accident. First, let $d$ be the total financial capacity of the centralized structure, and, second; let $d_{i}$ be the one of the operator $i, i=1,2 . d$ and $d_{i}$ include two parts. For the monopoly this value is $d=y+Q$, where $y$ is the monopolist's assets dedicated to the redress and $Q$ is the amount that insurance

\footnotetext{
${ }^{13}$ For engineers our economic assumptions could appear quite unrealistic. For instance Lochbaum (2000) notes the over-simplifications usually made to deal with this question: i) The plants are operating within technical specifications and other regulatory requirements, ii) Plant design and construction are completely adequate, iii) Plant aging does not occur; that is, equipment fails at a constant rate, iv) The reactor pressure vessels never fail, iv) Plant workers make few serious mistakes, v) Risk is limited to reactor core damage. If this set of assumptions cannot be insured for one plant, obviously it can hardly be done for a park even if plants belong to the same generation.
} 
companies accept to cover. Symmetrically, let $d_{i}=y_{i}+Q$ be the financial capacity of the individual operator $i, i=1,2$, (where $y_{i}$ is the wealth of $i$ due to repairs).

Assumption 3: The civil liability for nuclear accident is ruled by a capped strict liability regime where $c$ is the amount of the legal compensation (liability cap).

If $D$ is the total damage due to a severe harm, the institutional cap c is such that $0 \leq \mathrm{c} \leq \mathrm{D}$ (with the polar cases, $\mathrm{i}$ ) $\mathrm{c} \equiv 0$, which is a no-liability regime as in the Ex-USSR situation and, ii) $c \equiv D$, the standard strict liability regime as in India until 2010). For most nuclear countries, $0<c<D$. Assumption 3 means that insurance companies will not cover fully the cap and $Q<c$. The share $Q$ is identical whatever the exploitation structure, this because the cap is fixed whatever the production structure. This involves that the operators' own assets must be such that $y, y_{i}=c-Q$. Then, if $y<c-Q$ or $y_{i}<c-Q$, the operator runs the risk to go judgment-proof (Shavell, 1986). This situation is excluded from the field of the analysis simply because insurance companies will not insure the facility if the operators' assets are insufficient.

\subsubsection{The states of nature}

The elementary states of nature are denoted as follows. Let, the events $A$ and $B$ be respectively A:“a major accident occurs in a nuclear plant" and B: "business as usual" or still "no accident". A major accident induces the major damage D. Because the electronuclear park is constituted of two plants, the set of potential events (accident $A$, or no-accident $B$ ) may be described by the following sets:

- $H_{1}=(A, A)$ : Major accidents occurred on both plants 1 and 2,

- $H_{2}=(A, B)$ : A major accident occurred on plant 1 but not on plant 2,

- $H_{3}=(B, A):$ No accident occurred on plant 1, but a major one on plant 2,

- $\quad H_{4}=(B, B):$ No accident occurred on both plants 1 and 2 .

Then $\Omega^{*}$ is the set of sample: $\Omega^{*}=\left\{H_{1}, H_{2}, H_{3}, H_{4}\right\}$

The electro-nuclear park is controlled by a regulatory authority. This control can be strict (noted $S$ ), or sloppy $(\bar{S})$. A strict control is this set of necessary mitigation measures that the regulatory authority imposes to the operator to limit the occurrence of another catastrophic event after the occurrence of a major accident. The regulator has to induce the operator to take relevant safety means to avoid the duplication of an accident in the safe facility. In fact, after a major nuclear hazard, measures have to be taken to test out stations of same vintage. This matter of fact can be checked after the Fukushima accident. Indeed, everywhere in the World, national nuclear authorities are launching checking programs. Morgan Stanley (2006, p. 46) 
asserts that a severe accident in one reactor can "lead to the shutdown of the facility in question and, potentially, similar facilities that may be considered to present the same risks". This matter of fact can lead to slow down or interrupt the production. Consequently, the risk of other similar failure is significantly reduced to zero. This is true for both the centralized operator and the individual ones. The effective control applies for plants of the same generation in which identical defects may be suspected. Then, we can formulate the following assumption.

Assumption 4: After the occurrence of an ultra-hazardous accident, when strong control $S$ is exerted, the remaining safe plant is either slowed down or stopped temporarily.

We can add that the failure of a plant of a given generation means that the similar stations "do not meet the highest safety requirements and therefore pose safety risk must be identified and their safety performance must be raised to the necessary level. This task is primarily a national responsibility, but it should be facilitated through assistance measures by the international community", Milenin, Skokov and Supeno (1997).

The costs of controls, the slowing down or the temporarily stop down of the activity of the plant generates costs. This is expressed by the following assumption.

Assumption 5: After the occurrence of a major event, under assumption 4, the cost of stopping or slowing down the remaining plant is equal to $e,(c>e>0)$.

The cost $e$ should not be interpreted as a cost for care but rather as an opportunity cost such as the cost of increasing the load factor in the safe plant and checking the management of safety.

\subsubsection{The probability distribution of a major accident}

Here, identical plants allow us to consider that they share the same probability distribution of major failure. Each state of nature occurs with a given probability ${ }^{14}$. Hence, a major accident in a plant is reputed to occur with a probability $p(A) \in(0,1)$ or still $p$. Let the probability of the event $B$ ("business as usual or no accident"), be $p(B)=1-p(A)=$ $1-p$. In this industry the nature of the control, weak or sloppy, is common knowledge.

\footnotetext{
${ }^{14}$ It is difficult to assign a probability to what is considered as a rare event. As pointed by Schneider (2007) external and internal event may influence the probability distribution (external events are external flooding (Central of Blayes, France, 1999), Tsunami (Indian Ocean, 2004), external fires (Los Alamos 1996, 2000), tornado and Hurricanes (David Besse USA, 1998, Hurricane Andrex). Considering internal events, have to be understood the losses of coolant (Kozloduy, Bulgaria 2003), numerous turbine fires, and secondary cooling circuits. These events combine with human errors and violation of procedures. Hence, as such, the probability of the melting down of the core takes sense when considering the whole set of potential failure of the security system.
} 
Hence, there is no uncertainty from the operators' side about the type of control ${ }^{15}$. Both situations are clearly identified.

\subsection{The costs structures: infra-comparison between strong and weak control}

The nature of control as defined in 2.1.2 impacts on the expected costs of the industry:

- After a major accident, the level of the cap has to be paid deducing the amount of the insurance coverage $Q: c-Q$. Let $\mu$ the insurance premium $\mu$ this one is equal to $p Q=\mu$, (Shavell (1985)).

- When a strong control is exerted then, in the case of accident, the safe plant has to stop or slow down its activity for checking and this incurs some costs in compliance with assumption 5:

Now, we dispose of all elements to define the cost structure of an individual operator. To make easier the exposition we begin by describing the cost structure of the facility owned by a unique operator.

\subsubsection{The cost structure of an individual operator}

We will examine successively both cases: the weak and the strong control.

\section{i) Weak control}

Under a weak control, the regulatory authority does not induce the operator to reduce or to stop the activity level for some deep check after an accident and assumption 5 does not apply. As a consequence, the operator $i, i=1,2$ is not affected by the accident suffered by the other plant. He has only to pay the insurance premium $\mu$ whatever the state of nature. The entire situation may be described by the following table:

\footnotetext{
${ }^{15}$ The question of the probability of a major accident will be considered on a larger scale than the usual question of the melting of the core of a reactor. Indeed, it is the accumulated fission products in a reactor that forms the potential of radiation hazard. The melt down of the core of the reactor induces a severe accident. Safety is to prevent the release of these radioactive products and fuel isotopes. Accidents that issue on massive rejection of such material and threat populations and natural resources are particularly rare events. Indeed, in Western plants, an airtight containment reinforced concrete building (1.2 to 2.4 meters) tends to limit the effect of a melting of the nuclear core. Probabilistic methods (Probabilistic Risk Assessment) are used since the midst seventies (Murray, 2000). The object is to determine the probability of occurrence of an undesired event such "as core damage, breach of containment, or release of radioactivity, and to determine potential causes" Murray, (2000 p.277). Considering internal relationships, a catastrophic event does not occur suddenly. It supposes a succession of failure and events trees show the probabilistic path from a current incident to the disastrous event. That justifies the use of Bayesian approaches (Chen and Chu (1995)). Studies in the midst of the nineties show that the probability of the melting of the core in Europe of the nuclear plant is quite variable and depends on the generation of the power plant.

The ExternE study of 1995 considered a core meltdown probability of $10^{-5}$. However, the probability of such an event depends on the nature of reactors that have evolved throughout time following technical progress. Lembrechts, Slaper, Pearce and. Howarth (2000) show that the range of probability of core meltdown is comprised between $10^{-3}$ and $10^{-6}$ according the reactor generation. For instance, they report the studies concerning a study on two French reactors, a 900 MW Pressurized Water Reactor (PWR) and a 1300 MW PWR, indicated the following risk probability of a major core meltdown (World Bank, 1991) respectively $4.95 .10^{-5}$ and $1,05.10^{-5}$.
} 


\begin{tabular}{|c|c|c|}
\hline \multicolumn{3}{|c|}{ Cost structure of a strictly controlled operator } \\
\hline States of nature & Cost & Probabilities \\
\hline$H_{1}=(A, A)$ & $c+\mu-Q$ & $p^{2}$ \\
\hline$H_{2}=(A, B)$ & $c+\mu-Q$ & $p(1-p)$ \\
\hline$H_{3}=(B, A)$ & $\mu$ & $p(1-p)$ \\
\hline$H_{4}=(B, B)$ & $\mu$ & $(1-p)^{2}$ \\
\hline Sum & & 1 \\
\hline
\end{tabular}

Table 1

Hence, this situation is equivalent to be faced to only two states of nature because the plants are independent one from the other one and the sample set reduces to:

$$
\Omega_{\mathrm{i}}=\{\mathrm{A}, \mathrm{B}\}, i, i=1,2
$$

Thus, for the event $\mathrm{B}$, the costs incurred includes only the cost of the insurance premium, $\mu$ plus the one of the disastrous event, $\mathrm{A},(\mu+(c-Q))$. The expected costs $E C_{i}(\bar{S})$ $, i=1,2$, for the operator are then:

$$
\begin{aligned}
& E C_{i}(\bar{S})=\left[p^{2}+p(1-p)\right](c+\mu-Q)+\mu\left[\left((1-p)^{2}+p(1-p)\right]\right. \\
& \quad=p(\mu+(c-Q))+(1-p) \mu,
\end{aligned}
$$

And, after the simplification (where $p Q=\mu$ ):

$$
E_{i} C(\bar{S})=p c
$$

Consequently, under a weak control $(\bar{S})$, the expected cost of strict capped liability is equal to the expected cost of the accident proportionally to the cap $c$.

ii) Strong control

As mentioned above, after an accident on one plant, the remaining safe plant will be submitted to some strong costly control and/or breaks. These operations will incur a cost $e$ (following assumptions 4 and 5). Under a strong control, the state $H_{1}=(A, A)$ becomes unrealistic and a null probability is associated to it. This explains by the fact that the probability of a major accident is very weak, then, after the checking of the other plant, the probability of a new catastrophic event on it is still weaker. The states $H_{2}=(A, B)$ and $H_{3}=(B, A)$ which are not symmetric at the individual level deserves some attention. Consequently, if the operator undergoes the accident (event $\mathrm{H}_{2}$ ), he will have to pay $(c-Q)$ for repairs, while if his plant is safe, he will incur the opportunity cost $e$ only. The entire situation may be described by the following table 2 : 


\begin{tabular}{|c|c|c|}
\hline \multicolumn{3}{|c|}{ Cost structure of a strictly controlled operator } \\
\hline States of nature & Cost & Probabilities \\
\hline$H_{1}=(A, A)$ & $c+\mu-Q$ & 0 \\
\hline$H_{2}=(A, B)$ & $c+\mu-Q$ & $p$ \\
\hline$H_{3}=(B, A)$ & $\mu+\mathrm{e}$ & $p(1-p)$ \\
\hline$H_{4}=(B, B)$ & $\mu$ & $(1-p)^{2}$ \\
\hline Sum & & 1 \\
\hline
\end{tabular}

Table 2

The expected costs for the operator, $i, i=1,2, E C_{i}(S)$ are then:

$$
E C_{i}(S)=0(c+\mu)+p(c+\mu)+p(1-p)(\mu+\mathrm{e})+\mu(1-p)^{2}
$$

and, as previously by simplifying with $p Q=\mu$, we get:

$$
E C_{i}(S)=p(c+e)-e p^{2}
$$

We can check that the expected costs of a strictly controlled structure are higher or equal to a weak one, indeed:

$$
E C_{i}(S) \geq E_{i} C(\bar{S}) \Rightarrow p(c+e)-e p^{2} \geq p c,
$$

This is always true because after developing:

$$
e(1-p) \geq 0 \text {. }
$$

We deduce then the following proposition:

Proposition 1: Under the assumptions 1 to 5, a unique plant managed by a single operator incurs higher costs when it is strongly controlled rather than when the control is weak.

(Proof simple arithmetic and discussion above).

We can define now the cost structure for the monopolistic situation and compare then both industrial structures.

\subsubsection{The centralized structure}

The distribution of probability corresponding to each kind of control may be summarized in the following tables considering that the insurance premium is $\bar{\mu}$. As before, we will examine both cases: the weak and the strong control.

\section{i) Weak control}

Under a weak control the centralized organization can go on producing energy after a major accident by using his safe plant. Hence, as previously, the plants are fully independent one relative to the other one. We can draw then the following table: 


\begin{tabular}{|c|c|c|}
\hline \multicolumn{2}{|c|}{ Cost structure of a weakly controlled monopolistic operator } \\
\hline States of nature & Cost & Probabilities \\
\hline$H_{1}=(A, A)$ & $2 c+\bar{\mu}-2 Q$ & $p^{2}$ \\
\hline$H_{2}=(A, B)$ & $c+\bar{\mu}-Q$ & $p(1-p)$ \\
\hline$H_{3}=(B, A)$ & $c+\bar{\mu}-Q$ & $p(1-p)$ \\
\hline$H_{4}=(B, B)$ & $\bar{\mu}$ & $(1-p)^{2}$ \\
\hline Sum & & 1 \\
\hline
\end{tabular}

Table 3

The expected costs for the monopolistic operator under a weak control are then:

$$
\begin{aligned}
& E C(\bar{S})=(2 c+\bar{\mu}-2 Q) p^{2}+2 p(1-p)(c+\bar{\mu}-Q)+\bar{\mu}(1-p)^{2} \\
& E C(\bar{S})=2 p(c-Q)+\bar{\mu}
\end{aligned}
$$

The expected cost of liability is equal to the expected amount that the operator has to supply for repairs. This corresponds to the level of the cap minus the amount reimbursed by the insurance company plus the premium.

ii) Strong control

Under the strong control, assumption 5 applies and the monopolistic operator has to slow down or stop the production of the safe plant. He will incur the opportunity cost $e$ but equally the cost of due repairs. Hence, the table of cost is reproduced in the following:

\begin{tabular}{|c|c|c|}
\hline \multicolumn{2}{|c|}{ Cost structure of a strongly controlled monopolistic operator } \\
\hline States of nature & Cost & Explicit probabilities \\
\hline$H_{1}=(A, A)$ & $2 c+\bar{\mu}-2 Q$ & 0 \\
\hline$H_{2}=(A, B)$ & $c+\mathrm{e}+\bar{\mu}-Q$ & $p$ \\
\hline$H_{3}=(B, A)$ & $c+\mathrm{e}+\bar{\mu}-Q$ & $p(1-p)$ \\
\hline$H_{4}=(B, B)$ & $\bar{\mu}$ & $(1-p)^{2}$ \\
\hline Sum & & 1 \\
\hline
\end{tabular}

\section{Table 4}

The event $H_{2}$ means that once an accident has occurred on one plant, the operator has to stop or slow down immediately the activity of the other facility. Then, the payoff is $c+\mathrm{e}+\bar{\mu}-Q$, which occurs with a probability $p$. However, considering that a specific plant $j, j=1,2$ works "well" with a probability $(1-p)$ does not prevent, that the other one can fail with a probability $p$. This explains the state of nature $H_{3}$. This may be seen in the following decision tree. 


\section{[Insert Figure 1]}

A priori we do not know what plant among plant 1 and 2, will fail. Hence, because they are similar, we consider that Nature ( $\mathrm{N}$ in the decision tree) chooses with an equal probability $\pi=1 / 2$ what plant will suffer an accident. Rigorously, the expectation cost should write:

$$
\begin{aligned}
& E C(S)=\pi\left[(2 c+\bar{\mu}-2 Q) 0+p(c+e+\bar{\mu}-Q)+p(1-p)(c+e+\bar{\mu}-Q)+\bar{\mu}(1-p)^{2}\right] \\
& +(1-\pi)\left[(2 c+\bar{\mu}-2 Q) 0+p(c+e+\bar{\mu}-Q)+p(1-p)(c+e+\bar{\mu}-Q)+\bar{\mu}(1-p)^{2}\right][8]
\end{aligned}
$$

This writing is justified for plants presenting different risk level. This could be useful for the analysis of different generations for instance where the older generations may be considered as riskier than the younger ones. Here, this is not the case under assumption 1 $\left(\pi=\frac{1}{2}\right.$. Then, the expectation costs function writes:

$$
\begin{gathered}
E C(S)=(2 c+\bar{\mu}-2 Q) 0+p(c+e+\bar{\mu}-Q)+p(1-p)(c+e+\bar{\mu}-Q)+\bar{\mu}(1-p)^{2}= \\
E C(S)=2 p(c+e-Q)-p^{2}(c+e-Q)+\bar{\mu}
\end{gathered}
$$

If we compare $E C(S)$ and $E C(\bar{S})$ we can see that the advantage of a "weak-control" practice under a monopolistic situation gives not as clear results as in the previous case. Thus, we study conditions for having:

$$
E C(\bar{S})>E C(S) \text { or } E C(\bar{S}) \leq E C(S) .
$$

Considering $E C(\bar{S})>E C(S)$, this means that:

$$
2 p(c-Q)+\bar{\mu}>2 p(c+e-Q)-p^{2}(c+e-Q)+\bar{\mu}
$$

Or, still after simplifying:

$$
p>\frac{2 e}{(c+e-Q)}
$$

(With $c+e-Q>0$ ).

Then, $E C(\bar{S})>E C(S)$, this is true if $(c-Q)>e$. We can establish proposition 2:

Proposition 2: Under assumption 1 to 5, the level of the opportunity costs is essential to determine whether a strict controlled centralized organization generates higher expected costs than a decentralized structure. Consequently:

i) If $p>\frac{2 e}{(c+e-Q)}$, then a weak control incurs lesser costs than a centralized organization.

ii) If , in the opposite, $p \leq \frac{2 e}{(c+e-Q)}$, the centralized organization involves smaller costs.

The proof results from the above argument. 


\subsection{Decentralized vs centralized organization}

This section studies the efficiency of both types of organization. This consists in comparing each costs structure according the nature of the control. This analysis borrows some feature to the instruments of the contestable market theory in Baumol, Panzar and Willig (1982) because we refer to the sub-additivity of costs. However, our approach is different because we refer here to expected costs and we do not examine the sustainability question, i.e. the possibility for potential entrants to compete on prices. The question we deal with is to know whether it is more costly organizing monopolistically ultra-hazardous activities, or conversely, decentralizing it with independent operators. Here, the cost structure corresponds to the cost of civil liability.

\subsubsection{The case of weak control}

It is important to note that the insurance premium plays a fundamental role. Indeed, in what follows we shall study the conditions for which the expected cost of the decentralized structure is either higher or lesser than the monopolist one, i.e: $\sum_{i=1}^{2} E_{i} C(\bar{S}) \geq E C(\bar{S})$

or the reverse. $\sum_{i=1}^{2} E_{i} C(\bar{S})<E C(\bar{S})$. It is obvious that the value at which the insurer fixes the level of the premium is determinant for having either the cost of monopolistic organization higher than the decentralized one or the reverse.

Let us assume that: $\sum_{i=1}^{2} E_{i} C(\bar{S})<E(\bar{S})$. In what follows we consider that the level of the insurance premium of the decentralized organization is given and is equal to $\mu=p Q$.

From the previous definition we deduce that $: \sum_{i=1}^{2} E_{i} C(\bar{S})=2 p c$ and consequently:

$$
\begin{gathered}
\sum_{i=1}^{2} E_{i} C(\bar{S})<E C(\bar{S}) \Rightarrow 2 p c<2 p(c-Q)+\bar{\mu} \\
\text { or, } \\
\bar{\mu}>2 p Q=2 \mu
\end{gathered}
$$

Then, the condition for the monopolist operator to meet a higher expected cost of accident than under a decentralized structure is that his premium insurance should be more costly than for the individual operators. Otherwise, if $\bar{\mu}=2 \mu$, then, both organizations, monopoly or the decentralization one are equivalent.

Proposition 3: Under a weak control, under assumptions 1 to 5, if insurance premiums are defined proportionally for each plant ( $p Q=\mu$ for each individual operator and $\bar{\mu}=2 p Q$, for the monopolist), then the monopolistic and the decentralized organizations generates the same expected costs:

$$
\sum_{i=1}^{2} E_{i} C(\bar{S})=E C(\bar{S})
$$


Proof comes from the previous argument.

We have to note that this result is similar to the case in which insurance is not compulsory and may be set up at $\mu=\bar{\mu}=0$. Then, it is equivalent to exploit a ultra-hazardous risky park of plants under a monopolistic organization (unique operator) or under a decentralized organization (two independent operators).

\subsubsection{The case of strong control}

We analyze now the cost structure of the decentralized structure highly controlled. As before, we consider:

$$
\sum_{i=1}^{2} E C_{i}(S)=2\left(p(c+e)-e p^{2}\right)
$$

And we compare it with [9] and we determine the conditions for having:

i) $\quad$ Either $\sum_{i=1}^{2} E C_{i}(S) \geq E C(S)$, or

ii) $\quad \sum_{i=1}^{2} E C_{i}(S)<E C(S)$.

Then, let us analyze the relationship $\sum_{i=1}^{2} E C_{i}(S)<E C(S)$, this is equivalent to:

$$
2\left(p(c+e)-e p^{2}\right)<2 p(c+e-Q)-p^{2}(c+e-Q)+\bar{\mu}
$$

After developing, this relationship is true if there is $\bar{\mu}>0$, such that ${ }^{16}$ :

$$
\bar{\mu}>2 \mu+p^{2}(c+e-Q)
$$

Consequently, if the monopoly insurance premium is higher than the sum of the premium of the individual operators' plus $p^{2}(c+e-Q)$ (which is positive), then, it is only if the monopoly gets adverse insurance premium that the relationship:

$$
\sum_{i=1}^{2} E C_{i}(S)<E C(S) \text {, is verified. }
$$

Putting it otherwise, it is only if the insurance premiums are detrimental for the monopoly compared to the decentralized facilities that the centralized organization incurs higher costs. This is sufficient to establish proposition 4:

Proposition 4: Under strong control and under assumptions 1 to 5, if insurance premiums are defined proportionally for each plant (i.e. $p Q=\mu$ for each individual operator and $\bar{\mu}=2 p Q$, for the monopolist), then the monopolistic organization incurs lesser costs than the decentralized organization:

$$
\sum_{i=1}^{2} E C_{i}(S)<E C(S)
$$

With a monopolist insurance premium proportionally less than the one of the individual operators (i.e. $\bar{\mu} \leq 2 \mu$ ), then the advantage of the centralized situation is obvious, but this is an "unnatural" position and this result is not in the spirit of this model.

\footnotetext{
${ }^{16}$ Remember that $2 p Q=2 \mu$
} 


\section{Insurance and effort}

The above results are reached under the assumption that a major accident occurs under a once for all given probability. However, by increasing or decreasing the effort dedicated to improving safety, the operators may influence the level of risk and the operators may lower the accident probability by taking due care.

To deal with this point we adopt the Shavell (1986)'s presentation. Let $x$ be the operator's level of safety effort, $x \geq 0$. The probability of an accident modifies as $x$ varies, $1>p(x) \geq 0, p^{\prime}(x)<0$ and $p^{\prime \prime}(x)>0$. In the following, the analysis is restricted to the more realistic situation of a strong control.

The counterpart to the purchase of liability insurance is that the insurance company demands the highest level of care to the operators. Because of the specificity of the electronuclear production, it is not unrealistic to assume that asymmetric information between the operator and the insurance companies are almost impossible. Indeed, at all moment the level of safety can checked by the insurance company. The expected costs functions are modified, considering that the operators are risk neutral we represent the cost structure of a facility owned by a single operator by the following table:

\begin{tabular}{|c|c|c|}
\hline \multicolumn{2}{|c|}{ Cost structure, strict control, one facility and one operator } \\
\hline States of nature & Cost & Explicit probabilities \\
\hline$H_{1}=(A, A)$ & $c+\mu+x-Q$ & 0 \\
\hline$H_{2}=(A, B)$ & $c+\mu+x-Q$ & $p(x)$ \\
\hline$H_{3}=(B, A)$ & $\mu+\mathrm{e}+\mathrm{x}$ & $p(x)(1-p(x))$ \\
\hline$H_{4}=(B, B)$ & $\mu+x$ & $(1-p(x))^{2}$ \\
\hline Sum & & 1 \\
\hline
\end{tabular}

Table 5

And, the second one, the monopolistic cost structure:

\begin{tabular}{|c|c|c|}
\hline \multicolumn{3}{|c|}{ Cost structure of a strongly controlled monopolistic operator } \\
\hline States of nature & Cost & Explicit probabilities \\
\hline$H_{1}=(A, A)$ & $2 c+x+\bar{\mu}-2 Q$ & 0 \\
\hline$H_{2}=(A, B)$ & $c+x+e+\bar{\mu}-Q$ & $p(x)$ \\
\hline$H_{3}=(B, A)$ & $c+e+x+\bar{\mu}-Q$ & $p(x)(1-p(x))$ \\
\hline$H_{4}=(B, B)$ & $\bar{\mu}+x$ & $(1-p(x))^{2}$ \\
\hline Sum & & 1 \\
\hline
\end{tabular}




\section{Table 6}

We assume that the monopolist spends the same amount $x$ for care in for the whole park. From each one we draw the expected cost of civil liability. Consequently, for the "decentralized" operator:

$$
\begin{gathered}
E C_{i}(x)=p(x)(c+x+\mu-Q)+p(x)(1-p(x))(\mu+e+x)+(\mu+x)(1-p(x))^{2}= \\
E C_{i}(x)=x+\mu+p(x)(c+e-Q)-e p(x)^{2}
\end{gathered}
$$

And for the monopolist operator:

$$
\begin{gathered}
E C(x)=p(x)(c+x+e+\bar{\mu}-Q)+p(x)(1-p(x))(c+x+e+\bar{\mu}-Q) \\
+(\bar{\mu}+x)(1-p(x))^{2}= \\
E C(x)=x+\bar{\mu}-(c-Q)(-2+p(x)) p(x)
\end{gathered}
$$

We can check that these functions are convex. They decrease for low values of $x$ and increase as $x$ grows because $1 \geq p(x) \geq p(x)^{2} \geq 0$ and for high values of $x, p(x)$ and $p(x)^{2}$ tend to 0 . This element is important to determine what structure will give the highest level of safety. This can be done directly by considering that the level of the premium is identical for both organizations i.e. $\bar{\mu}=2 \mu$. To compare fairly between these structures, we assume that, under the decentralized structure, both plants are gathered but keep their management autonomy.

We study then two conjectures. Concerning the first one, the insurance premium is given and the operators have to adapt $x$ to it. Concerning the second one, while in the second one, the insurance policies is adapted to the care level supplied by operators, i.e; $\bar{\mu}(x)=$ $p(x) Q n,($ for $n=1,2)$.

\subsection{The insurance premium is given}

We can set up the following proposition:

Proposition 5: Under assumptions 1 to 5, when civil liability is ruled by a capped liability regime, a monopolistic organization induces a higher level of care than a decentralized one in so far that the value of the cap is such that $c-e-Q>0$. If $x_{f}^{*}$ and $x_{\varphi}^{*}$, represent respectively the optimum effort level of the decentralized and the centralized organization, then $x_{f}^{*}<x_{\varphi}^{*}$.

\section{Proof:}

We replace the expected costs functions respectively by

$f$ and $\varphi$ such that:

$$
\left.f(x)=E C_{i}(x)=x+\mu+p(x)(c+e-Q)-e p(x)^{2}\right), \quad i=1,2 .
$$

For the decentralized structure, and:

$$
\varphi(x)=E C(x)=x+2 \mu-(c-Q)(-2+p(x)) p(x)
$$


for the monopolist organization.

We can check that $\varphi(x)$ and $f(x)$ are related each other:

$$
\varphi(x)=f(x)+\mu-(c-e-Q)(-1+p(x)) p(x)
$$

Then, considering that if $x_{f}^{*}$ is that level of effort such that cancels $f^{\prime}\left(x_{f}^{*}\right) \leq 0$, with equality for $x_{f}^{*}>0$, then:

$$
\varphi^{\prime}\left(x_{f}^{*}\right)=0+(c-e-Q)\left(1-2 p\left(x_{f}^{*}\right)\right) p^{\prime}\left(x_{f}^{*}\right)
$$

If $x_{f}^{*}<x_{\varphi}^{*}$ where $x_{\varphi}^{*}$ is that optimal effort level which minimizes $\varphi(x)$ it sufficient to show that $\varphi^{\prime}\left(x_{f}^{*}\right)<0$. This means that the monopolist situation supplies a higher optimal level of effort than the decentralized situation and the reverse if $x_{f}^{*} \geq x_{\varphi}^{*}$. Indeed, as $\varphi(x)$ and $f(x)$ are increasing functions, if $\varphi^{\prime}\left(x_{f}^{*}\right)<0$ when $f^{\prime}\left(x_{f}^{*}\right)=0$, then $\varphi\left(x_{f}^{*}\right)$ has not yet reached its minimum level. This will be done for $x_{\varphi}^{*}, x_{\varphi}^{*}>x_{f}^{*}$.

Now, we examine the conditions for which:

$$
\varphi^{\prime}\left(x_{f}^{*}\right)<0 \Rightarrow \varphi^{\prime}\left(x_{f}^{*}\right)=(c-e-Q)(1-2 p(x)) p^{\prime}\left(x_{f}^{*}\right)<0
$$

this expression is verified if $1-2 p(x)>0$, this means that $1 / 2>p(x)$, this by knowing that $(c-e-Q)>0$ (the cap is supposed to be higher than the cumulated value of the opportunity cost and the level of the coverage) and $p^{\prime}\left(x_{f}^{*}\right)<0$ (assumption on the density of the probability distribution). This last condition is easily checked because $p(x)$ is very small. Nobody will take the risk to invest in the electro-power generation with a risk of major failure such that $\frac{1}{2} \leq p(x)$. Hence, $\varphi^{\prime}\left(x_{f}^{*}\right)<0$, for $1 / 2>p(x)$. As a consequence, $x_{\varphi}^{*}>x_{f}^{*}$ and the proposition 5 is verified.

\subsection{Variable insurance premium according the level of care}

Now we consider the situation in which the insurance adapts its premium to the level of effort of the agent: $\mu(x)=Q p(x)$ and $\bar{\mu}(x)=2 Q p(x)$. we apply the same argument as previously. That means that the insurance premium depends on the level of effort achieved by the operators. We draw the following proposition:

Proposition 6: Under assumption 1 to 5, under a capped liability regime, and when the insurance premium is defined proportionally to the level of care $x$, where $\mu=Q p(x)$ and $\bar{\mu}=2 Q p(x)$, then the monopolistic organization induces a higher level of care than the decentralized organization, i.e. $x_{f}^{*}<x_{\varphi}^{*}$, where $x_{f}^{*}$ and $x_{\varphi}^{*}$, are respectively the optimum effort level of the decentralized and the centralized organization.

Proof: As previously, we define respectively the following functions $\varphi(x)$ and $f(x)$ as: 


$$
\begin{array}{ll}
- & \varphi(x)=p(x)(c+x+e+2 Q p(x)-Q)+p(x)(1-p(x))(c+x+e+ \\
& 2 Q p(x)-Q)+(2 Q p(x)+x)(1-p(x))^{2} \\
- & f(x)=p(x)(c+x+Q p(x)-Q)+p(x)(1-p(x))(Q p(x)+e+x)+ \\
& \left.(Q p(x)+x)(1-p(x))^{2}\right)
\end{array}
$$

As previously, we express $\varphi(x)$ as a function of $f(x)$ :

$$
\varphi(x)=f(x)+c p(x)+e p(x)-c p(x)^{2}+Q p(x)^{2}
$$

and we seek for the first derivative function:

$$
\varphi^{\prime}(x)=f^{\prime}(x)+c p^{\prime}(x)+e p^{\prime}(x)-2 c p(x) p^{\prime}(x)+2 Q p(x) p^{\prime}(x)
$$

As before we calculate $\varphi^{\prime}\left(x_{f}^{*}\right)$ with $x_{f}^{*}$ such that $f^{\prime}\left(x_{f}^{*}\right)=0$ :

$$
\varphi^{\prime}\left(x_{f}^{*}\right)=0+\left(c+e-2(c-Q) p\left(x_{f}^{*}\right)\right) p^{\prime}\left(x_{f}^{*}\right)
$$

It can be shown that this value is negative. Indeed, $p^{\prime}\left(x_{f}^{*}\right)<0$, and $(c+e)-$ $\left.2(c-Q) p\left(x_{f}^{*}\right)\right)$ is positive. To see that, let us note that $p\left(x_{f}^{*}\right)$ is always positive or null, hence we have to define, the conditions for which:

$$
c+e>2(c-Q) p\left(x_{f}^{*}\right) \Rightarrow \frac{c+e}{2(c-Q)}>p\left(x_{f}^{*}\right)
$$

This condition is always verified because $c>Q$, and $c, e>0$, the insurance company cannot allocate more than the cap. Consequently, $\varphi^{\prime}\left(x_{f}^{*}\right)<0$, and $\varphi(x)$ has not reached its minimum, at $x_{f}^{*}$ then $x_{f}^{*}<x_{\varphi}^{*}$. The centralized structure ensures a higher level of safety compared to the decentralized organization.

Remark : The insurance premium question: The previous results have been reached without specific assumptions on the level of the insurance premium. More precisely, it has been assumed that the level of insurance is identical whatever the competitive structure. This subject is becoming highly sensitive between authors who think that the level of insurance premium is considerably too high, taking account of the level of effective coverage (Faure and Fiore (2008)) and authors who consider that this premium is too low because of an insufficient level of exposure from the insurance company side (Caroll, and Froggart, (2007)). Implicitly, we have admitted that the premium is equal to $\bar{\mu}=p Q n$, where $n$ is the number of station as in Faure-Fiore (2009). However, we are not led to bring some judgment about the actual level of insurance premium of real companies. Indeed, our analysis considers only that under similar and proportional insurance premium the cost of safety is lesser under a centralized system than under a decentralized one. Our results are depending on the relationships between the amount of $c, e$ and $Q$. Two of these values are depending on decisions of the Authorities, the amount of the ceiling $c$ and on the combined choices of the 
insurance market and the insurance corporations i.e. the level of $Q$. Hence, if the lag between $c$ and $Q$ is sufficiently thin such that $c-e-Q<0$ then $\varphi^{\prime}\left(x_{f}^{*}\right)>0$ and with the same argument than above, $x_{\varphi}<x_{f}$, i.e. the decentralized structure insures a better safety. This point is important. Indeed, it means either that the insurance companies accept to increase their share in compensation or that the level of the ceiling is diminishing. We recall that this level may be such that $0 \leq c \leq D$. Hence, the lesser the level of the cap, the larger is the road for a decentralized organization. However, as seen in the first paragraph (see also Caroll, and Froggart, (2007)), the landslide tendency is to increase the level of caps.

The question of the negative value of $(c-Q)-e$, however, has to be considered seriously. Indeed, it corresponds to the increased resort to private insurance due to the pooling of insurers as Pelzer (2007, p.55) shows it by underlining the US and the German experiences. We can quote it: "The operators' pooling systems established in Germany and in the US prove their capacity to deploy many times the amounts required under the revised nuclear liability conventions and in particular the amounts offered by the insurance industry. The money will be provided to cover the legal liability of the operator liable without excluding certain risks from coverage".

Consequently, when the lag between $c$ and $Q$ diminishes (for $e$ given), then the decentralized structure may become more efficient than the centralized one.

\section{Conclusion and Policy recommendations}

The public authorities aim at insuring the best safety coverage of populations against the risks of the electro-nuclear industry. The present paper has been limited at assessing the cost of safety only, letting aside the working costs of this industry. We show that a natural monopoly organization generates higher costs of care level than a decentralized management. This involves inducing dispersed operators to cluster them together. It is then the interest of the new structure to minimize its expected global safety and damage costs. This is done by increasing the level of safety expenses (proposition 6). As a corollary, the condition for increased safety is a high level of control from the regulatory authority side. Hence, the more stringent are becoming the Regulatory Authority, the more they favor scale economies (proposition 4). The above results are independent of a privatization concern because in the nuclear sector, many ways can be invoked to privatize the production park. For instance, the stations can be privatized as separate entities, which may not be a viable competitive scheme. 
The safer scheme is then to consider that privatization may be achieved through the transfer of shares of a unique portfolio to different partners. Hence, this analysis has specifically focused on the question of the advantages of splitting the exploitation of a nuclear park independently of the question of privatization of assets.

If it is impossible to maintain a centralized structure, then a decentralized organization should be accompanied by deep changes in the insurance infrastructure. Indeed, this one should favor an increase of the involvement of insurances and re-insurance companies. This is shown in the final remark of section 3. This result joins the contemporaneous trend that tends to extend the cover by insurance companies in this ultra-hazardous sector.

These proposals could bring some confusion without more explanation. Indeed, the previous results do not mean that considering concrete present situations, the safety level of decentralized structures shows inefficiencies in so far that they comply perfectly with the actual norms of the regulatory authorities. Precisely, our argument means that if, for instance, safety standards have to increase, then as a consequence, they require more care effort (this lead to diminish theoretically the probability of an accident) whereas safety costs are near the equilibrium level $x_{f}^{*}$. Then the centralized monopolistic organization generates lower equilibrium costs compared to a decentralized one. 


\section{References}

AEN-OCDE, 2000. L'énergie nucléaire face à la concurrence sur les marchés de l'électricité, Paris OCDE.

Ampere, 2000. "Rapport de la Commission pour l'Analyse des Modes de Production de l'Électricité et le Redéploiement des Énergies (AMPERE)", Bruxelles.

Baumol, W. J., Panzar, J. C., and Willig, R. D., 1982) Contestable Markets and the Theory of Industry Structure, New York: Harcourt Brace Jovanovich, Inc. 1982.

Bickel, Peter and Friedrich, Rainer (eds), 2005. ExternE Methodology, Update,European Commission, http://ec.europa.eu/research/energy/pdf/kina_en.pdf.

Chen, G., Chu, T.L, 1995. "estimation of Initiating Event Distribution at Nuclear Power Plants by Bayesian Procedures", $2^{\text {nd }}$ Issat international conference on reliability and Quality in Design, March, 8-10, Orlando, FL, USA.

http://www.osti.gov/bridge/purl.cover.jsp;jsessionid=78BFFB5E462E1C08EE31A335 BCE7B979?purl=/203480-Ir5O69/webviewable/

Carroll S. and Froggatt, A. 2007. "Nuclear Third Party Insurance The Nuclear Sector's "Silent" Subsidy State of Play and Opportunities in Europe", Conference Discussion Paper for The Future of Nuclear Energy in A Carbon Constrained World, November 5th 2007 New York.http://www.npolicy.org/files/DRAFT-20071105-Froggatt-

NuclearThirdPartyInsurancePaper.pdf

Dubin . J.A. and G.S. Rothwell, 1990. "Subsidy to Nuclear Power Through PriceAnderson Liability Limit,"Contemporary, Policy Issues, p 3, 7 (1990).

Faure, M.1 G. and Borre, T. V. 2008. "Compensating Nuclear damage: A Comparative Economic Analysis of the US and International Liability Schemes", Environmental Law \& Policy Review, Vol.33, pp. 219-286.

European Commission, 2005. "Legal Study For The Accession Of Euratom to the Paris Convention on Third Party Liability in the Field of Nuclear Energy" FINAL REPORT, TREN/CC/01-2005.

Faure M. G., Fiore K., 2009. "An Economic Analysis Of The Nuclear Liability Subsidy School of Law”, Pace Environmental Law Review, Vol.26, pp.419-448.

Gollier, C. Proult, D.;Thais F., Walgenwitz G. 2005. "Choice of nuclear power investments under price uncertainty: Valuing modularity", Energy Economics, vol. 27, n. 4, July, p. 667-685.

Intergovernmental Panel on Climate Change, Fourth Assessment Report, 2007.

Hayns M. R., 1999. "The Evolution Of Probabilistic Risk Assessment In The Nuclear Industry", Institution of Chemical Engineers, Part B, May, Trans ChemE, Vol 77.

Heyes A and C. Liston-Heyes, 1998. "Subsidy for Nuclear Power Through the PriceAnderson Liability Limit,"Contemporary Economic Policy, January,pp. 122-124.

Heyes, A. and Liston-Heyes C. 2000. "An empirical analysis of the Nuclear Liability Act (1970) in Canada", Resource and Energy Economics, vol. 22(1), pp. 91-101.

Heyes, A. and Liston-Heyes C. 2000. "Capping Environmental Liability: The Case of North American Nuclear Power”, The Geneva Papers, Volume 25, Number 2, April 2000, pp. 196-202(7).

International Energy Atomic Agency 1999) "Strategies for competitive nuclear power plants" November, IAEA-TECDOC-1123.

Lembrechts, J. Slaper, H., D.W. Pearce, A. Howarth 2000. "Technical Report on Nuclear Accidents and other Major Accidents in Europe: an integrated economic and environmental assessment", May, RIVM report 481505013, National Institute of Public Health and The Environment. 
Levendis, J.,Block W. and Morrel J., "Nuclear Power", Journal of Business Ethics, Volume 67, Number 1 / août 2006.

Linares, P., Conchado, A., 2009), "The economics of new nuclear power plants in liberalized electricity markets, August 17, 2009, 10th IAEE European Conference Energy, Policies and Technologies for Sustainable Economies 7 - 10 September 2009.

Lochbaum D., 2000. "Nuclear Plant Risk Studies, Failing the Grade", Union of Concerned Scientists, UCS Publications

Milenin S., Skokov S., Supeno E., 1997. " The Chornobyl [Chernobyl] Accident and the Future of Nuclear Energy: The Path Towards Safety and Sustainability", Ukrainian Research Institute, Harvard University, Working Papers, $\mathrm{n}^{\circ} 1$.

http://www.huri.harvard.edu/workpaper/chornob1.html

MIT, 2003. The Future of Nuclear Power. An Interdisciplinary MIT Study

MIT, 2009. Update on the cost of nuclear power. An Interdisciplinary MIT Study.

MORGAN STANLEY, 2006) «EDF, base prospectus".

http://finance.edf.com/fichiers/fckeditor/Commun/Finance/Investisseurs/Annee/2007/

EMTN2007BaseProspectus_va.pdf.

Murray, R.L., 2000. "Nuclear Energy", 5th edition, Butterworth-Heinemann. Oxford England, Massachusetts, USA.

NEA, 2000. Nuclear Energy Agency, "Reduction of Capital Costs of Nuclear Power Plants", NEA4372, Nuclear Energy Agency, Organisation For Economic Co-Operation and Development, ISBN 92-64-02153-1 Nuclear Energy Institute. U.S. Nuclear Plant Sales

http://www.nei.org/resourcesandstats/documentlibrary/reliableandaffordableenergy/gr aphicsandcharts/usnuclearplantsales/ 2003 ,

OECD, 2003; "Nuclear Electricity Generation: What Are the External Costs?" OECD

OECD, 2006. International Nuclear Law in the Post-Chernobyl Period.

http://www.nea.fr/law/chernobyl/SCHWARTZ.pdf

Pelzer, N., 2007. 'International Pooling of Operators' Funds: An Option to Increase the Amount of Financial Security to Cover Nuclear Liability?" Discussion Paper for the IAEA INLEX Group Meeting on 21-22 June 2007.

http://www.nea.fr/law/nlb/nlb-79/037-055-Article\%20N.\%20Pelzer.pdf

Roques, F.A., Nuttall, W.J., Newbery, D.M., de Neufville, R. and Connors, S., 2006. "Nuclear power: a hedge against uncertain gas and carbon prices?" The Energy Journal, 37(4): 1-23

Schwartz, J. A., 2006. "International Nuclear Third Party Liability Law: The Response to Chernobyl",

http://www.npec-web.org/files/DRAFT-20071105-Froggatt-

NuclearThirdPartyInsurancePaper.pdf

Rothwell G., 2001. "Further Comments on Subsidy to Nuclear Power through the Price Anderson Liability Limit,"mimeo, August 2001.

Rogovin, M., Frampton, G.T., 1980. "Three Miles Island”, Vol.1, part.1, A report to the commissioners and to the public, SPECIAL INQUIRY GROUP, U.S. Nuclear Regulatory Commission, Washington, D.C.

Shavell, S., 1984. "A Model of the Optimal Use of Liability and Safety Regulation", RAND Journal of Economics, 15, 271-80.

Shavell, S., 1986. "The Judgement Proof Problem", International Review of Law and Economics, $\mathrm{N}^{\circ} 6,45-58$.

Shavell, S., 2005. "Minimum asset requirements and compulsory liability insurance as solution to the judgment-proof problem", RAND Journal of Economics, Vol.36, $\mathrm{N}^{\circ} 1$, Spring, 2005, pp.63-77. 
Schneider M. (proj. coord.), 2007."Residual Risk, An Account of Events in Nuclear Power Plants Since the Chernobyl Accident in 1986", Green European Free Alliance.

http://www.greens-efa.org/cms/topics/dokbin/181/181995.residual_risk@en.pdf.

Trebilcock M. and Winter, R.A, 1997. "The economics of nuclear accident law”,International Review of Law and Economics, Vol. 17 (2), pp. 215-243.

Varley C. and Paffenbarger J., 1998. "Electricity Market Competition and Nuclear Power'The Uranium Institute, Twenty Third Annual International Symposium. http://www.world-nuclear.org/sym/1998/varley.htm 
Figure 1 Decision tree for the centralized situation with strong control

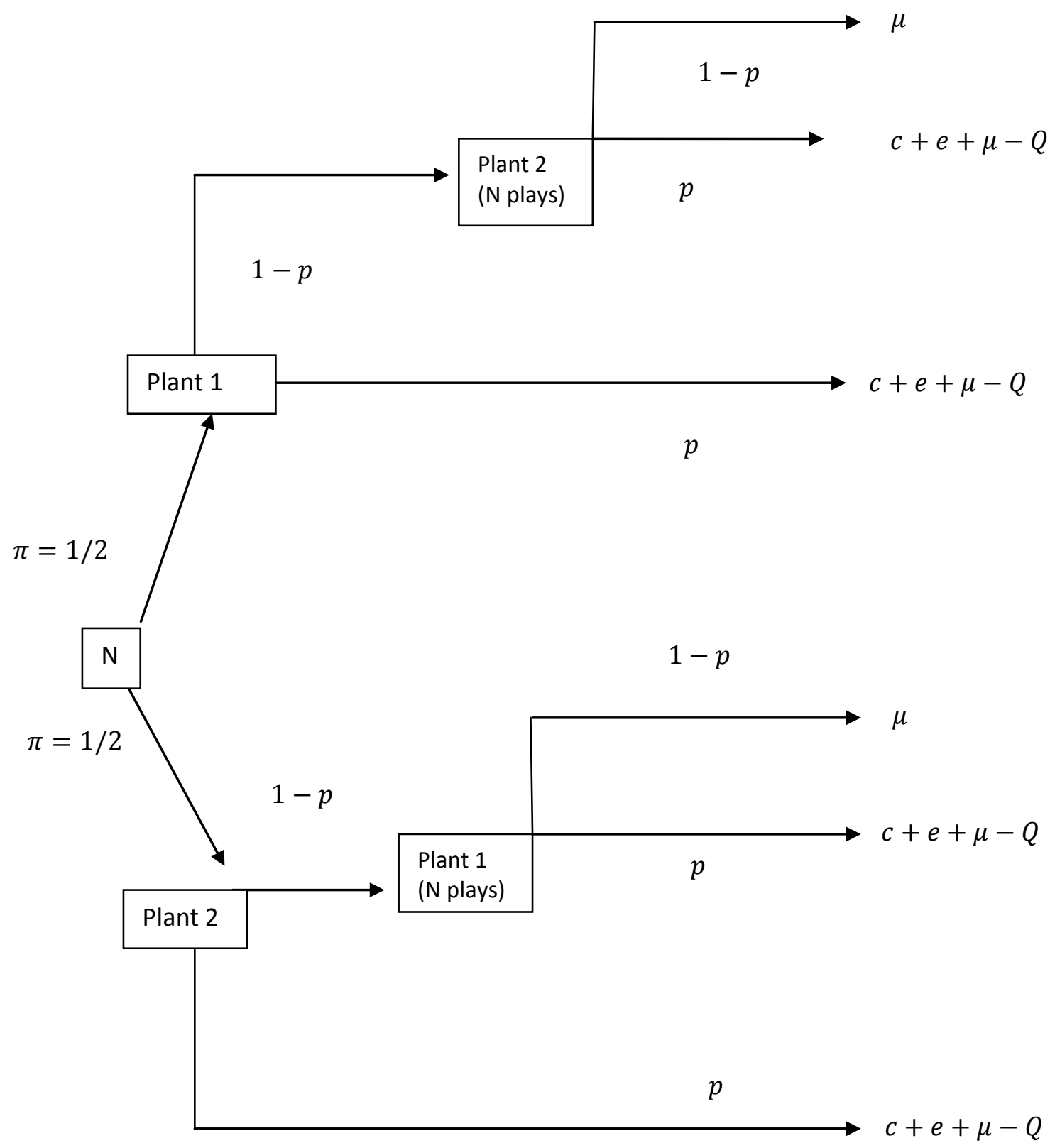




\section{NOTE DI LAVORO DELLA FONDAZIONE ENI ENRICO MATTEI}

\section{Fondazione Eni Enrico Mattei Working Paper Series}

Our Note di Lavoro are available on the Internet at the following addresses:

http://www.feem.it/getpage. aspx?id=73\&sez=Publications\&padre=20\&tab=1

http://papers.ssrn.com/sol3/JELJOUR_Results.cfm?form_name=journalbrowse\&journal_id=266659 http://ideas.repec.org/s/fem/femwpa.html

http://www.econis.eu/LNG=EN/FAM?PPN=505954494

http://ageconsearch.umn.edu/handle/35978

http://www.bepress.com/feem/

\section{NOTE DI LAVORO PUBLISHED IN 2011}

Anna Alberini, Will Gans and Daniel Velez-Lopez: Residential Consumption of Gas and Electricity in the U.S.: The Role of Prices and Income

Alexander Golub, Daiju Narita and Matthias G.W. Schmidt: Uncertainty in Integrated Assessment Models of Climate Change: Alternative Analytical Approaches

Reyer Gerlagh and Nicole A. Mathys: Energy Abundance, Trade and Industry Location

Melania Michetti and Renato Nunes Rosa: Afforestation and Timber Management Compliance Strategies in Climate Policy. A Computable General Equilibrium Analysis

Hassan Benchekroun and Amrita Ray Chaudhuri: "The Voracity Effect" and Climate Change: The Impact of Clean Technologies

Sergio Mariotti, Marco Mutinelli, Marcella Nicolini and Lucia Piscitello: Productivity Spillovers from Foreign MNEs on Domestic Manufacturing Firms: Is Co-location Always a Plus?

Marco Percoco: The Fight Against Geography: Malaria and Economic Development in Italian Regions Bin Dong and Benno Torgler: Democracy, Property Rights, Income Equality, and Corruption Bin Dong and Benno Torgler: Corruption and Social Interaction: Evidence from China

Elisa Lanzi, Elena Verdolini and Ivan Haščič: Efficiency Improving Fossil Fuel Technologies for Electricity Generation: Data Selection and Trends

Stergios Athanassoglou: Efficient Random Assignment under a Combination of Ordinal and Cardinal Information on Preferences

Robin Cross, Andrew J. Plantinga and Robert N. Stavins: The Value of Terroir: Hedonic Estimation of Vineyard Sale Prices

Charles F. Mason and Andrew J. Plantinga: Contracting for Impure Public Goods: Carbon Offsets and Additionality

Alain Ayong Le Kama, Aude Pommeret and Fabien Prieur: Optimal Emission Policy under the Risk of $\underline{\text { Irreversible Pollution }}$

Philippe Quirion, Julie Rozenberg, Olivier Sassi and Adrien Vogt-Schilb: How CO2 Capture and Storage Can Mitigate Carbon Leakage

Carlo Carraro and Emanuele Massetti: Energy and Climate Change in China

ZhongXiang Zhang: Effective Environmental Protection in the Context of Government Decentralization Stergios Athanassoglou and Anastasios Xepapadeas: Pollution Control: When, and How, to be Precautious Jūratè Jaraitè and Corrado Di Maria: Efficiency, Productivity and Environmental Policy: A Case Study of Power Generation in the EU

Giulio Cainelli, Massimiliano Mozzanti and Sandro Montresor: Environmental Innovations, Local Networks and Internationalization

Gérard Mondello: Hazardous Activities and Civil Strict Liability: The Regulator's Dilemma Haiyan Xu and ZhongXiang Zhang: A Trend Deduction Model of Fluctuating Oil Prices

Athanasios Lapatinas, Anastasia Litina and Eftichios S. Sartzetakis: Corruption and Environmental Policy: An Alternative Perspective

Emanuele Massetti: A Tale of Two Countries:Emissions Scenarios for China and India Xavier Pautrel: Abatement Technology and the Environment-Growth Nexus with Education Dionysis Latinopoulos and Eftichios Sartzetakis: Optimal Exploitation of Groundwater and the Potential for a Tradable Permit System in Irrigated Agriculture

Benno Torgler and Marco Piatti. A Century of American Economic Review

Stergios Athanassoglou, Glenn Sheriff, Tobias Siegfried and Woonghee Tim Huh: Optimal Mechanisms for Heterogeneous Multi-cell Aquifers

Libo Wu, Jing Li and ZhongXiang Zhang: Inflationary Effect of Oil-Price Shocks in an Imperfect Market: A Partial Transmission Input-output Analysis

Junko Mochizuki and ZhongXiang Zhang: Environmental Security and its Implications for China's Foreign $\underline{\text { Relations }}$

\section{Based on Historical Cumulative Emission Per Capita}

Dirk Rübbelke and Pia Weiss: Environmental Regulations, Market Structure and Technological Progress in Renewable Energy Technology - A Panel Data Study on Wind Turbines

Nicola Doni and Giorgio Ricchiuti: Market Equilibrium in the Presence of Green Consumers and Responsible Firms: a Comparative Statics Analysis 
